\title{
FAKTOR-FAKTOR YANG BERHUBUNGAN DENGAN KURANGNYA MINAT IBU TERHADAP PENGGUNAAN METODE KONTRASEPSI IMPLANT DI WILAYAH PUSKESMAS PONRE KECAMATAN GANTARANG KABUPATEN BULUKUMBA
}

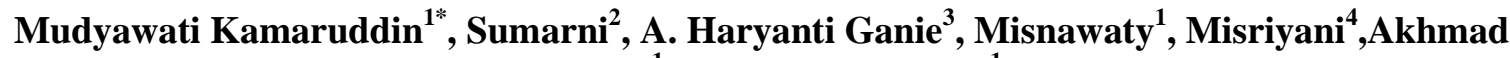 \\ Rivandi $^{1}$, Dewi Purnamasari ${ }^{1}$
}

\author{
${ }^{1}$ Program Studi Kebidanan, Akademi Kebidanan Tahirah Al Baeti, Bulukumba, Sulawesi Selatan, \\ ${ }^{2}$ Puskesmas Caile, Kabupaten Bulukumba, Sulawesi Selatan, Indonesia \\ ${ }^{3}$ Puskesma Ponre, Kabupaten Bulukumba, Sulawesi Selatan, Indonesia \\ ${ }^{4}$ Fakultas Kedokteran, Universitas Alkhairaat, Jl. Diponegoro Palu 94221, Sulawesi Tengah, Indonesia \\ *Corresponding author: Telp: +628111520603, email: mudya07@gmail.com
}

\begin{abstract}
ABSTRAK
Kontrasepsi adalah obat atau alat untuk mencegah terjadinya konsepsi/kehamilan. Implant merupakan salah satu metode kontrasepsi hormonal yang efektif, yang diinsersikan tepat di bawah kulit, dilakukan pada bagian dalam lengan atas atau di bawah siku melalui insisi tunggal dalam bentuk kipas, tidak permanen dan dapat mencegah terjadinya kehamilan antara tiga hingga lima tahun. Tujuan penelitian untuk mengetahui faktor-faktor yang berhubungan dengan kurangnya minat ibu terhadap penggunaan metode kontrasepsi implant di Wilayah Puskesmas Ponre Kecamatan Gantarang Kabupaten Bulukumba. Jenis penelitian yang digunakan adalah analitik studi cross sectional, dengan populasi semua ibu pengguna kontrasepsi hormonal sejumlah 33 responden dengan teknik total sampling. Instrumen pengumpulan data yang digunakan dalam penelitian ini yaitu lembar kuisioner, kemudian dianalisa secara univariat dan bivariat. Hasil penelitian menunjukkan terdapat hubungan yang signifikan antara sumber informasi dengan minat ibu terhadap penggunaan metode kontrasepsi implant dengan $p$ value $=$ 0,016 . Sedangkan dua variabel yang lain pendidikan dan pengetahuan ibu sebagai responden tidak terdapat hubungan dengan minat ibu terhadap penggunaan metode kontrasepsi implant dengan $p$ value masing-masing adalah 0,943 dan 0,147 . Dan dari 33 responden yang diteliti yang minat terhadap penggunaan kontrasepsi implant sebanyak 3 orang $(9,1 \%)$ dan non implant sebanyak 30 orang $(90,9 \%)$. Hal ini menunjukkan faktor sumber informasi sangat berperan penting untuk menyebarkan informasi dan pengetahuan tentang metode kontrasepsi implant. Diharapkan petugas atau tenaga kesehatan dapat memberikan konseling tentang macam-macam metode kontrasepsi pada ibu calon pengguna kontrasepsi sebagai tambahan pengetahuan kepada wanita usia subur melalui kegiatan warga dengan membagikan selebaran tentang semua alat kontrasepsi termasuk implant.
\end{abstract}

Kata Kunci : Kontrasepsi implant, pendidikan, pengetahuan, sumber informasi.

\section{ABSTRACT}

Contraception is a drug or tool to prevent conception or pregnancy. Implant is one of the effective hormonal contraceptive methods, which is inserted directly under the skin, performed on the inside of the upper arm or under the elbow through a single incision. It is not permanent and can prevent pregnancy within three to five years. This study aims to determine the factors of associated to the lack of maternal interest in using implantable contraceptive methods in the Community Health Center of Ponre, Gantarang District, Bulukumba Regency. This research used cross sectional analytic study with a population of 33 hormonal contraception users using total sampling techniques. Questionnaire sheets as data collection instruments used in this study. Data analyzed univariately and bivariately. The results showed that there was a significant relationship between information resources and maternal interest in using implantable contraceptive methods with $p$ value was 0.016. Meanwhile, the other two variables, education 
and knowledge of mothers, there was no relationship to maternal interest in using implantable contraceptive methods with $p$ values of 0.943 and 0.147 respectively. While of the 33 respondents surveyed who were interested in using implantable contraception only 3 people (9.1\%) and non-implants were 30 people $(90.9 \%)$. This shows that the information resources is very important to disseminate information and knowledge about implantable contraceptive methods. In the future, it is expected that health workers or staff will be able to provide counseling on various contraceptive methods to prospective contraceptive mothers in addition to their knowledge through community activities by distributing leaflets containing all contraceptive devices including implants.

Keywords: Implant contraception, education, knowledge, information sources

\section{PENDAHULUAN}

Program Keluarga Berencana (KB) merupakan usaha yang dilakukan untuk mengatur jumlah, jarak dan usia melahirkan melalui promosi, perlindungan dan bantuan mendapatkan hak reproduksi untuk menciptakan keluarga yang berkualitas ${ }^{1}$.

Sejalan dengan Peraturan Pemerintah Republik Indonesia Nomor 87 tahun 2014, mengenai Perkembangan Kependudukan dan Pembangunan Keluarga, KB dan Sistem Informasi Keluarga, program KB merupakan upaya mengurangi kematian ibu karena kondisi ibu yang terlalu muda, terlalu sering melahirkan, terlalu rapat dan terlalu tua melahirkan. Program KB juga bermaksud meningkatkan kualitas, kesejahteraan lahir dan kebahagiaan batin keluarga sehingga timbul rasa aman, tentram dan harapan masa depan yang lebih baik. Pasangan usia subur (PUS) yang merupakan kelompok wanita usia subur (WUS) antara usia 15 - 49 tahun merupakan sasaran program $\mathrm{KB}^{1}$.

Dalam mendorong dan membangun peningkatan peran serta masyarakat dalam membangun keluarga kecil yang mandiri dilakukan gerakan KB Nasional melalui strategi Rencana Pembangunan Jangka Menengah (RPJM) tahun 2004 sampai 2009 yaitu meningkatkan penggunaan Metode Kontrasepsi Jangka Panjang (MKJP) seperti IUD (Intra Uterine Device), implant (susuk) dan sterilisasi dengan Metode Operatif Wanita (MOW) dan Metode Operatif Pria (MOP) (BKKBN (2011) dalam Dini P.R., 2014).

Menurut Kamus Kependudukan \& Keluarga Berencana (2011:69), Kontrasepsi adalah obat ataualat untuk mencegah terjadinya konsepsi (kehamilan). Jenis kontrasepsi ada dua macam, yaitu kontrasepsi yang mengandung hormonal (pil, suntik dan implant) dan kontrasepsi non-hormonal (IUD, kondom).Implant salah satu metode kontrasepsi hormonal yang efektif, tidak permanen dan dapat mencegah terjadinya kehamilan antara tiga hingga lima tahun.

Menurut data dari World Health Oganisazition (WHO) tahun 2008 tentang persentasi metode kontrasepsi dapat dilihat pada tabel 1

Tabel 1 Metode kontrasepsi menurut WHO tahun 2008

\begin{tabular}{lc}
\hline Metode Kontrasepsi & $\%$ pemakaian \\
\hline Kondom & $80-90$ \\
Pil & $90-96$ \\
Suntik & $95-97$ \\
Susuk (Implant) & $97-99$ \\
IUD & $94-95$ \\
Vasektomi & $99,4-99,8$ \\
Tubektomi & $99,5-99,9$ \\
\hline
\end{tabular}

Sumber : (Lis Sinsin (2008) dalam Salviana, Hasifah, Suryani S., 2013:2).

Alat kontrasepsi suntikan lebih mayoritas dipilih dan diminati oleh masyarakat dibandingkan dengan metode KB MKJP yaitu sebesar $51,21 \%$, memilih pil $40,02 \%, 4,93 \%$ memilih implant, memilih IUD 2,27\% dan metode lainnya $1,11 \%^{2}$. Persentase peserta $\mathrm{KB}$ aktif menurut metode kontrasepsi di Indonesia Tahun 2014 dijelaskan pada tabel 2. 
MEDIKA ALKHAIRAAT : JURNAL PENELITIAN KEDOKTERAN DAN KESEHATAN 2(1): 37-48

e-ISSN: 2656-7822, p-ISSN: 2657-179X

Tabel 2 Persentase peserta KB aktif berdasarkan metode kontrasepsi di Indonesia tahun 2014.

\begin{tabular}{lcc}
\hline & \multicolumn{2}{c}{ Jumlah dan \% } \\
\cline { 2 - 3 } & Jumlah & $\%$ \\
\hline Pasangan Usia Subur (PUS) & 47.019 .002 & \\
Peserta KB aktif & 35.202 .908 & 74,87 \\
Metode Kontrasepsi & & \\
IUD & 3.896 .081 & 11,07 \\
MOW & 1.238 .749 & 3,52 \\
MOP & 241.642 & 0,69 \\
Implant & 3.680 .816 & 10,46 \\
Kondom & 1.110 .341 & 3,15 \\
Suntikan & 16.734 .917 & 47,54 \\
Pil $\quad 8.300 .362$ & 23,58 \\
\hline \multicolumn{1}{c}{ Sumber : Profil Kesehatan Indonesia 2014, Cet.2015. }
\end{tabular}

Sedangkan persentase peserta KB aktif menurut Metode Kontrasepsi di Provinsi Sulawesi Selatan Tahun 2014 (Tabel 3).

Tabel 3 Peserta KB aktif menurut metode kontrasepsi di

\begin{tabular}{lc}
\multicolumn{2}{c}{ Provinsi Sulawesi Selatan (dalam \%) } \\
\hline & Jumlah $(\%)$ \\
\hline Pasangan Usia Subur (PUS) & 1.387 .345 \\
Peserta KB aktif & 1.012 .913 \\
& $(73,01 \%)$ \\
Metode Kontrasepsi & \\
IUD & $4,41 \%$ \\
MOW & $1,81 \%$ \\
MOP & $0,91 \%$ \\
Implant & $11,99 \%$ \\
Kondom & $6,22 \%$ \\
Suntikan & $45,58 \%$ \\
Pil & $29,81 \%$ \\
\hline
\end{tabular}

Sumber : BKKBN, 2014 dalam Profil Kesehatan Indonesia 2014, Cet.2015.

Meskipun implant merupakan alat penggunaan metode kontrasepsi implant masih kontrasepsi yang sangat penting bagi sulit untuk ditingkatkan, hal ini disebabkan kesehatan reproduksi ibu serta dapat bahwa tidak semua metode kontrasepsi cocok mengendalikan laju pertambahan penduduk dengan kondisi setiap orang.

namun penggunaan implant ini menurun Berdasarkan data dari Dinas Kesehatan dibandingkan dengan metode kontrasepsi Kabupaten Bulukumba dan dari Puskesmas hormonal yang dapat menimbulkan resiko bila Ponre pada Desember 2015 dapat dijelaskan penggunaannya dalam waktu panjang. pada tabel 4 berikut:

Kesertaan wanita usia subur dalam 
Tabel 4 Peserta KB aktif menurut metode kontrasepsi Dari Dinas Kesehatan Kab. Bulukumba dan Puskesmas Ponre (dalam \%)

\begin{tabular}{lcccc}
\hline & \multicolumn{4}{c}{ Jumlah dan \% } \\
\cline { 2 - 5 } & \multicolumn{2}{c}{ Bulukumba } & \multicolumn{3}{c}{ Ponre } \\
\cline { 2 - 5 } & Jumlah & $\%$ & Jumlah & $\%$ \\
\hline $\begin{array}{l}\text { Pasangan Usia Subur } \\
\text { (PUS) }\end{array}$ & - & - & 4603 & \\
Peserta KB aktif & 44057 & 58,50 & 3404 & 74,04 \\
Metode Kontrasepsi & 779 & 1,08 & 7 & 0,20 \\
AKDR / IUD & 105 & 0,14 & 9 & 0,26 \\
MOW & 19 & 0,04 & 0 & 0 \\
MOP & 1364 & 1,81 & 78 & 2,29 \\
Implant & 1628 & 2,16 & 96 & 2,82 \\
Kondom & 31289 & 41,55 & 1830 & 53,76 \\
Suntikan & 8873 & 11,78 & 1384 & 40,65 \\
Pil & & & & \\
\hline
\end{tabular}

Sumber : Profil Dinas Kesehatan dan Puskesmas Ponre Kab.Bulukumba 2015.

Berdasarkan Tabel 4 menunjukkan bahwa penggunaan kontrasepsi implant masih rendah dan kurang dipilih oleh WUS, sehingga terlihat berbanding terbalik dengan tujuan pemerintah yang mencanangkan tingginya penggunaan MKJP seperti implant.

Berdasarkan alasan di atas, maka peneliti tertarik untuk melakukan penelitian tentang faktor - faktor yang berhubungan dengan kurangnya minat ibu terhadap penggunaan metode kontrasepsi implant di Wilayah Puskesmas Ponre, Kecamatan Gantarang, Kabupaten Bulukumba tahun 2016.

\section{METODOLOGI}

\section{Jenis dan Rancangan Penelitian}

Dalam penelitian ini menggunakan jenis penelitian analitik studi cross sectional. Cross sectional merupakan metode penelitian yang dilakukan dengan mengobservasi atau mengukur variabel pada saat tertentu, bukan berarti semua subyek diamati tepat pada saat yang samatetapi tiap subyek hanya diobservasi dan pengukuran variabeldilakukan pada saat pemeriksaan tersebut ${ }^{3}$.

\section{Lokasi dan Waktu Penelitian}

\section{Lokasi}

Lokasi penelitian ini dilaksanakan di Wilayah Puskesmas Ponre, Kecamatan Gantarang, Kabupaten Bulukumba tahun 2016.Peneliti tertarik melakukan penelitian di lokasi tersebut karena pengguna kontrasepsi implant masih kurang, kebanyakan ibu memilih kontrasepsi suntikan dan pil.

2. Waktu

Penelitian ini dilaksanakan selama kurang lebih 1 bulan mulai tanggal 27 April sampai dengan 31 Mei 2016.

Populasi, Sampel, dan Teknik Pengambilan Sampel

1. Populasi

Populasi adalah wilayah generalisasi yang terdiri atas objek / objek yang mempunyai kuantitas dan karakteristik tertentu yang ditetapkan oleh peneliti untuk dipelajari dan kemudian ditarik kesimpulannya ${ }^{4}$.

Populasi dalam penelitian ini adalah semua ibu pengguna kontrasepsi hormonal yang dilakukan pada tanggal 27 April - 31 Mei 2016 di Wilayah Puskesmas Ponre, Kec. Gantarang, Kab. Bulukumba sebanyak 33 responden.

2. Sampel

Sampel adalah bagian dari jumlah dan karakteristik yang dimiliki oleh populasi (Sugiono (2002) dalam Munawaroh, 2013:61).

3. Teknik Pengambilan Sampel

Adapun teknik pemilihan sampel dalam penelitian ini yaitu teknik Total Sampling. Total sampling yaitu semua 
populasi dijadikan sebagai sampel. Jadi besar sampel dalam penelitian ini yaitu semua ibu pengguna kontrasepsi hormonal selama penelitian berlangsung sebanyak 33 orang.

a. Kriteria Inklusi

Kriteria inklusi adalah karakteristik umum subyek penelitian pada populasi target dan pada populasi terjangkau (Sastroasmoro S. dan Ismael S., 2014:56).

1) Semua akseptor KB yang menggunakan metode kontrasepsi hormonal di Wilayah Puskesmas Ponre, Kecamatan Gantarang, Kabupaten Bulukumba tahun 2016.

2) Semua akseptor yang bersedia menjadi responden dan mau mengisi kuesioner penelitian.

b. Kriteria Eksklusi

Kriteria eksklusi adalah sebagian subyek yang memenuhi kriteria inklusi harus dikeluarkan dari studi oleh karena berbagai sebab (Sastroasmoro S. dan Ismael S., 2014:57).

1) Akseptor KB yang tidak menggunakan metode kontrasepsi hormonaldi Wilayah Puskesmas Ponre,
Kecamatan Gantarang, Kabupaten Bulukumba tahun 2016.

2) Akseptor yang tidak bersedia menjadi responden dan tidak mau mengisi kuisioner penelitian.

\section{Variabel Penelitian}

1. Variabel Independen (variabel bebas)

Variabel independen merupakan variabel yang menjadi sebab perubahan atau timbulnya variabel dependen (terikat) ${ }^{5}$. Variabel independen dalam penelitian ini meliputi pengetahuan, pendidikan dan sumber informasi.

2. Variabel Dependen

Variabel dependen ini merupakan variabel yang dipengaruhi atau menjadi akibat karena variabel bebas ${ }^{5}$. Variabel dependen dalam penelitian ini yaitu minat penggunaan kontrasepsi.

\section{DefinisiOperasional}

Definisi operasional dibuat untuk memudahkan pengumpulan data dan menghindarkan perbedaan interpretasi serta membatasi ruang lingkup variabel (Munawaroh, 2013:71).

Tabel 5 Definisi Operasional faktor - faktor yang berhubungan dengan kurangnya minat ibu terhadap penggunaan metode kontrasepsi Implant

\begin{tabular}{|c|c|c|c|c|}
\hline Variabel & Definisi Operasional & $\begin{array}{l}\text { Cara } \\
\text { Ukur }\end{array}$ & Hasil Ukur & $\begin{array}{l}\text { Skala } \\
\text { Ukur }\end{array}$ \\
\hline $\begin{array}{l}\text { (Dependen) } \\
\text { Minat } \\
\text { Penggunaan } \\
\text { Kontrasepsi }\end{array}$ & $\begin{array}{l}\text { Responden yang } \\
\text { menggunakan metode } \\
\text { kontrasepsi hormonal. }\end{array}$ & Checklist & $\begin{array}{l}\text { 1. Tidak Menggunkan } \\
\text { Implant }=0 \\
\text { 2. Menggunakan Implant } \\
=1\end{array}$ & Nominal \\
\hline $\begin{array}{l}\text { (Independen) } \\
\text { Pengetahuan }\end{array}$ & $\begin{array}{l}\text { Segala sesuatu yang } \\
\text { diketahui oleh pengguna } \\
\text { alat kontrasepsi tentang } \\
\text { metode kontrasepsi } \\
\text { Implant. }\end{array}$ & Checklist & $\begin{array}{l}\text { 1. Kurang }(<55 \%) \\
\text { 2. Cukup }(56 \%-75 \%) \\
\text { 3. Baik }(76 \%-100 \%)\end{array}$ & Ordinal \\
\hline Pendidikan & $\begin{array}{l}\text { Pendidikan terakhir dari } \\
\text { ibu yang menggunakan } \\
\text { metode kontrasepsi } \\
\text { hormonal. }\end{array}$ & Checklist & $\begin{array}{l}\text { 1. SD } \\
\text { 2. SMP } \\
\text { 3. SMA } \\
\text { 4. Akademi / Sederajat / } \\
\text { Lebih tinggi }\end{array}$ & Ordinal \\
\hline $\begin{array}{l}\text { Sumber } \\
\text { Informasi dari } \\
\text { Petugas } \\
\text { Kesehatan } \\
\text { (Konseling) }\end{array}$ & $\begin{array}{l}\text { Informasi yang } \\
\text { didapatkan pengguna KB } \\
\text { dari petugas kesehatan } \\
\text { tentang metode } \\
\text { kontrasepsi Implant. }\end{array}$ & Checklist & $\begin{array}{l}\text { 1. Tidak mendapat } \\
\text { informasi }=0 \\
\text { 2. } \text { Mendapatkan } \\
\text { informasi }=1\end{array}$ & Nominal \\
\hline
\end{tabular}




\section{Teknik Pengumpulan Data}

Data yang diperoleh terbagi atas dua jenis data, yaitu :

\section{Data primer}

Data primer adalah data yang diperoleh langsung dari responden yang menjadi objek dalam penelitian (Munawaroh, 2013:82) yaitu berupa lembar kuisioner.

2. Data sekunder

Data sekunder adalah data yang digunakan untuk mendukung data primer (Munawaroh, 2013:82) yang diperoleh dari Dinas Kesehatan Kabupaten Bulukumba dan Puskesmas Ponre, Kecamatan Gantarang, Kabupaten Bulukumba.

\section{Instrumen Penelitian}

Instrumen yang digunakan dalam penelitian ini yaitu lembar kuisioner, kuisioner adalah suatu alat pengumpulan data mengenai suatu masalah yang umumnya banyak menyangkut kepentingan umum atau orang banyak $^{6}$.

Jumlah soal dalam kuisioner yang digunakan yaitu untuk tingkat pengetahuan sebanyak 15 pertanyaan dan 5 pertanyaan untuk sumber informasi.

\section{Pengolahan Data}

Pengolahan data merupakan kegiatan lanjutan setelah pengumpulan data dilaksanakan. Proses pengolahan data setelah data terkumpul dilakukan beberapa tahap, yaitu :

a) Editing, dilaksanakan setelah menghimpun data di lapangan dan memeriksa kelengkapan instrumen.

b) Koding (pengkodean) yaitu data yang telah diedit diberi identitas sehingga memiliki arti tertentu pada saat dianalisis.

c) Scoring, yaitu memberikan nilai jawaban pada setiap jawaban responden sehingga setiap jawaban responden dapat diberikan skor. d) Entering, yaitu memasukkan data kedalam tabel yang disediakan untuk diolah secara manual atau memakai program komputer.

e) Tabulating, yaitu kegiatan memasukkan data yang telah diperoleh untuk disusun berdasarkan variabel yang diteliti.

\section{Analisis Data}

Analisis data adalah rangkaian kegiatan penelaahan, pengelompokkan, sistematisasi, penafsiran, dan verifikasi data agar sebuah fenomena memiliki nilai sosial, akademisi, dan ilmiah (Brannen. Julia (2008) dalam Munawaroh, 2013:83).

\section{HASIL DAN PEMBAHASAN \\ HASIL}

Analisis univariat dilakukan terhadap tiap variabel untuk melihat tampilan distribusi frekuensi setiap variabel.

\section{a. Pendidikan}

Dalam penelitian ini, pendidikan merupakan variabel independen dan hasil distribusi frekuensi terhadap pendidikan responden dengan menggunakan data primer yang diolah secara SPSS 16.0 dapat dilihat pada tabel 6 di bawah ini:

Tabel 6. Distribusi frekuensi berdasarkan pendidikan respondendi Puskesmas Ponre Kec. Gantarang, Kab. Bulukumba

\begin{tabular}{ccc}
\hline Pendidikan & Frekuensi & $\begin{array}{c}\text { Persentase } \\
(\%)\end{array}$ \\
\hline SD & 24 & 72,7 \\
SMP & 2 & 6,1 \\
SMA & 3 & 9,1 \\
Akademi & 4 & 12,1 \\
Total & 33 & 100,0
\end{tabular}

Sumber: Data Primer yang diolah SPSS 16.0(Sumarni, 2016).

Berdasarkan tabel di atas, total responden sebanyak 33 orang, dengan mayoritas berpendidikan Sekolah Dasar (SD) 
sebanyak 24 responden $(72,7 \%)$ dan disusul berturut-turut Akademi4 responden $(12,1 \%)$, Sekolah Menengah Atas (SMA) 3 responden $(9,1 \%)$ dan Sekolah Menengah Pertama 2 responden (SMP) $(6,1 \%)$.

\section{b. Pengetahuan}

Pengetahuan merupakan variabel independen dalam penelitian ini dan pengetahuan yang diukur adalah pengetahuan responden tentang kontrasepsi implant. Adapun hasil distribusi frekuensi terhadap pengetahuan responden dengan menggunakan data primer yang diolah secara SPSS 16.0dapat dilihat pada tabel 7 di bawah ini:

Tabel 7. Distribusi frekuensi berdasarkan pengetahuan respondententang kontrasepsi implantdi Puskesmas Ponre Kec. Gantarang, Bulukumba

\begin{tabular}{ccc}
\hline Pengetahuan & Frekuensi & $\begin{array}{c}\text { Persentase } \\
(\%)\end{array}$ \\
\hline Baik & 11 & 33,3 \\
Cukup & 11 & 33,3 \\
Kurang & 11 & 33,3 \\
Total & 33 & 100,0
\end{tabular}

Sumber: Data Primer yang diolah SPSS 16.0(Sumarni, 2016).

Tabel 7 di atas menunjukkan bahwa, pengetahuan responden tentang kontrasepsi implant di Wilayah Puskesmas Ponre Kec. Gantarang Kab. Bulukumba berada dalam kategori baik, cukup dan kurang masingmasing 11 responden sebesar 33,3\%.

\section{c. Sumber Informasi}

Hasil distribusi frekuensi terhadap sumber informasi yang diperoleh responden dengan menggunakan data primer yang diolah secara SPSS 16.0 dapat dilihat pada tabel 8 di bawah ini:

Tabel 8. Distribusi frekuensi berdasarkan sumber informasi yang didapatkan respondententang kontrasepsi implantdi
Puskesmas Ponre Kec. Gantarang, Kab. Bulukumba

\begin{tabular}{ccc}
\hline $\begin{array}{c}\text { Sumber } \\
\text { Informasi }\end{array}$ & Frekuensi & $\begin{array}{c}\text { Persentase } \\
(\%)\end{array}$ \\
\hline $\begin{array}{c}\text { Non } \\
\text { Kesehatan } \\
\text { Tenaga }\end{array}$ & 21 & 63,6 \\
$\begin{array}{c}\text { Kesehatan } \\
\text { Total }\end{array}$ & 33 & 36,4 \\
& & 100,0
\end{tabular}

Sumber: Data Primer yang diolah SPSS 16.0(Sumarni, 2016).

Keterangan: Non kesehatan $=$ Bukan tenaga kesehatan

Berdasarkan tabel 8, sumber informasi yang diperoleh responden dari bukan tenaga kesehatan merupakan frekuensi terbanyak dari 33 responden yaitu sebanyak 21 responden atau $63,6 \%$.

\section{d. Minat Penggunaan Kontrasepsi}

Adapun hasil distribusi frekuensi terhadap minat penggunaan kontrasepsi ibu dengan menggunakan data primer yang diolah secara SPSS 16.0 dapat dilihat pada tabel 9 di bawah ini:

Tabel 9. Distribusi frekuensi berdasarkan minat penggunaan kontrasepsi di Puskesmas Ponre Kec. Gantarang, Bulukumba

\begin{tabular}{ccc}
\hline $\begin{array}{c}\text { Minat } \\
\text { Penggunaan } \\
\text { Kontrasepsi }\end{array}$ & Frekuensi & $\begin{array}{c}\text { Persentase } \\
(\%)\end{array}$ \\
\hline Non & 30 & 90,9 \\
Implant & & \\
Implant & 3 & 9,1 \\
Total & 33 & 100,0
\end{tabular}

Sumber: Data Primer yang diolah SPSS 16.0(Sumarni, 2016).

Pada tabel 9 di atas dapat diketahui minat penggunaan kontrasepsi dari 33 responden mayoritas menggunakan kontrasepsi non implant sebanyak 30 orang $(90,9 \%)$ dibanding dengan penggunaan kontrasepsi implantyang hanya diminati oleh 3 orang $(9,1 \%)$. 


\section{Analisis Bivariat}

Analisis bivariat dilakukan untuk melihat hubungan tiap variabel independen dan variabel dependen.Jika data tidak berdistribusi normal, untuk skala nominal menggunakan uji Chi-Square sedangkan jika berskala ordinal maka menggunakan uji Spearman's rho. a. Uji Spearman's rho variabel pendidikan dan minat ibu terhadap penggunaan metode kontrasepsi

Adapun hasil uji Spearman'srho antara pendidikan dan minat responden terhadap penggunaan metode kontrasepsi dapat dilihat pada di bawah ini:

Tabel 10. Hubungan antara pendidikan dan minat responden terhadap penggunaan metode kontrasepsi di Wilayah Puskesmas Ponre Kec. Gantarang, Bulukumba

\begin{tabular}{cccccccc}
\hline Pendidikan & \multicolumn{3}{c}{$\begin{array}{c}\text { Minat penggunaan } \\
\text { kontrasepsi }\end{array}$} & \multirow{2}{*}{ Total } & $\begin{array}{c}p \\
\text { value }\end{array}$ \\
\cline { 2 - 5 } & \multicolumn{3}{c}{$\begin{array}{c}\text { Non } \\
\text { Implant }\end{array}$} & \multicolumn{1}{c}{ Implant } & & & \\
\cline { 2 - 6 } & $\mathrm{N}$ & $\%$ & $\mathrm{~N}$ & $\%$ & $\mathrm{~N}$ & $\%$ & \\
\hline SD & 22 & 66,7 & 2 & 6,1 & 24 & 72,7 & \\
SMP & 2 & 6,1 & 0 & 0,0 & 2 & 6,1 & 0,943 \\
SMA & 2 & 6,1 & 1 & 3,0 & 3 & 9,1 & \\
Akademi & 4 & 12,2 & 0 & 0,0 & 4 & 12,1 & \\
\hline Total & 30 & 90,9 & 3 & 9,1 & 33 & 100,0 & \\
\hline
\end{tabular}

Sumber: Data Primer yang diolah SPSS 16.0 (Sumarni, 2016).

Tabel 10 di atas adalah hasil uji Spearman's rho hubungan antara tingkat pendidikan terhadap minat penggunaan kontrasepsi dari 33 responden. Berdasarkan tingkat pendidikan, responden dengan tingkat SD mayoritas menggunakan kontrasepsi non implant sebesar $66,7 \%$ diikuti dengan responden yang berpendidikan akademi sebesar $12,1 \%$. Sedangkan responden dengan latar belakang pendidikan SMP dan SMA masing-masing hanya $6,1 \%$ memilih kontrasepsi non implant. Adapun minat responden terhadap kontrasepsi implant sangatlah kurang, dari 33 responden hanya $6,1 \%$ yang berpendidikan SD dan 3,0\% dengan tingkat pendidikan SMA, sedangkan responden dengan tingkat pendidikan yang lain sama sekali tidak menggunakan kontrasepsi implant tersebut.

$$
\text { Berdasarkan uji Spearman's }
$$
rhodidapatkan $p$ value sebesar 0,943 , dimana $p$ value ini lebih besar daripada a value yaitu $0,943>0,05$, hal inimenunjukkan bahwa tidak ada hubungan yang signifikan antara pendidikan dan minat ibu terhadap penggunaan metode kontrasepsi di Wilayah Puskesmas Ponre Kec. Gantarang, Kab. Bulukumba.

\section{b. Hasil uji Spearman's rhovariabel} pengetahuan dan minat ibu dalam penggunaan metode kontrasepsi

Hasil uji Spearman's rhoantara pengetahuan dan minat responden terhadap penggunaan metode kontrasepsi, dapat dilihat pada tabel 11 berikut: 
Tabel 11. Hubungan antara pengetahuan dan minat responden terhadap penggunaan metode kontrasepsi di Wilayah Puskesmas Ponre Kec.Gantarang, Kab.Bulukumba

\begin{tabular}{|c|c|c|c|c|c|c|c|}
\hline \multirow[t]{3}{*}{ Pengetahuan } & \multicolumn{4}{|c|}{$\begin{array}{l}\text { Minat penggunaan } \\
\text { kontrasepsi }\end{array}$} & \multirow{2}{*}{\multicolumn{2}{|c|}{ Total }} & \multirow[t]{3}{*}{$\begin{array}{c}p \\
\text { value }\end{array}$} \\
\hline & \multicolumn{2}{|c|}{ Non Implant } & \multicolumn{2}{|c|}{ Implant } & & & \\
\hline & $\mathrm{N}$ & $\%$ & $\mathrm{~N}$ & $\%$ & $\mathrm{~N}$ & $\%$ & \\
\hline Baik & 9 & 27,3 & 2 & 6,1 & 11 & 33,3 & 0,147 \\
\hline Cukup & 10 & 30,3 & 1 & 3,0 & 11 & 33,3 & \\
\hline Kurang & 11 & 33,3 & 0 & 0,0 & 11 & 33,3 & \\
\hline Total & 30 & 90,9 & 3 & 9,1 & 33 & 100,0 & \\
\hline
\end{tabular}

Sumber: Data Primer yang diolah SPSS 16.0 (Sumarni, 2016).

Tabel 11 adalah hasil ujiSperman's rho hubungan antara pengetahuan responden terhadap metode kontrasepsi. Berdasarkan tabel di atas menunjukkan pengetahuan responden dengan kategori baik, cukup maupun kurang masing-masing sebesar $27,3 \% ; 30,3 \%$ dan $33,3 \%$ cenderung menggunakan kontrasepsi non implant dibandingkan dengan penggunaan kontrasepsi implant yang hanya diminati oleh ibu yang berkategori berpengetahuan baik $(6,1 \%)$ dan cukup $(3,0 \%)$.

Sedangkan $p$ value yang diperoleh adalah 0,147 nilai ini lebih besar daripada avalue $=$ $0,05(0,147>0,05)$, hal ini berarti tidak ada

Tabel 12. Hubungan antara sumber informasi dan minat responden terhadap penggunaan metode kontrasepsi di Wilayah Puskesmas Ponre Kec. Gantarang, Kab. Bulukumba

\begin{tabular}{ccccccccc}
\hline \multirow{2}{*}{$\begin{array}{c}\text { Sumber } \\
\text { Informasi }\end{array}$} & \multicolumn{3}{c}{$\begin{array}{c}\text { Minat penggunaan } \\
\text { kontrasepsi }\end{array}$} & & Total & $\begin{array}{c}p \\
\text { value }\end{array}$ \\
\cline { 2 - 4 } & \multicolumn{3}{c}{$\begin{array}{c}\text { Non } \\
\text { Implant }\end{array}$} & \multicolumn{2}{c}{ Implant } & & & \\
\cline { 2 - 5 } & $\mathrm{N}$ & $\%$ & $\mathrm{~N}$ & $\%$ & $\mathrm{~N}$ & $\%$ & \\
\hline $\begin{array}{c}\text { Non } \\
\text { Kesehatan } \\
\text { Tenaga }\end{array}$ & 21 & 63,6 & 0 & 0,0 & 21 & 63,6 & 0,016 \\
Kesehatan & 9 & 27,3 & 3 & 9,1 & 12 & 36,4 & \\
\hline Total & 30 & 90,9 & 3 & 9,1 & 33 & 100,0 & \\
\hline
\end{tabular}

Sumber: Data Primer yang diolah SPSS 16.0 (Sumarni, 2016).

Keterangan: Non kesehatan = bukan tenaga kesehatan

Berdasarkan hasil hubungan antara sumber informasi dan minat responden terhadap penggunaan kontrasepsi di atas, dari 33 responden yang berminat pada kontrasepsi 
non implant lebih banyak mendapatkan informasi dari informan yang bukan tenaga kesehatan (63,6\%), sedangkan yang mendapatkan informasi dari tenaga kesehatan hanya sebesar 27,3\%. Adapun responden yang berminat terhadap kontrasepsi implant sebesar $9,1 \%$ setelah mendapatkan informasi dari tenaga kesehatan.

Berdasarkan uji Chi-Square didapatkan $p$ value senilai0,016, dimana $p$ value ini lebih kecil daripada a value $=0,05(0,016<0,05)$, hal ini berarti ada hubungan antara sumber informasi dan minat responden terhadap penggunaan metode kontrasepsi di Wilayah Puskesmas Ponre Kec.Gantarang, Kab. Bulukumba.

\section{PEMBAHASAN}

Implant merupakan salah satu metode kontrasepsi jangka panjang pada wanita yang diinsersikan tepat di bawah kulit, dilakukan pada bagian bawah lengan atas atau di bawah siku melalui insisi tunggal dalam bentuk kipas yang efektif mencegah terjadinya kehamilan antara tiga hingga lima tahun. Metode kontrasepsi ini sangat dianjurkan oleh pemerintah, akan tetapi banyak wanita yang kurang berminat mengikuti metode kontrasepsi ini dengan berbagai alasan.

Penelitian ini dilakukan untuk mengetahui faktor-faktor yang berhubungan dengan kurangnya minat ibu terhadaap penggunaan metode kontrasepsi implant akan menjadi suatu penelitian yang sangat berguna untuk membantu pemerintah dalam mewujudkan misi dan visi kesehatan kedepan.

Berdasarkanhasil penelitian yang telah dilakukan terhadap 33 responden yang terdiri dari tingkat pendidikan yang beragam yaitu SD, SMP, SMA dan Akademi di Puskesmas Ponre Kec. Gantarang, Kab. Bulukumba menunjukkan sebagian besar responden adalah berpendidikan SD sebanyak 24 orang (72,7\%). Hal ini mungkin disebabkanmasyarakat di Kecamatan Gantarang belum terlalu paham betapa pentingnya pendidikan serta ekonomi yang tidak mendukung dan sebagian kecil masyarakatnya pendatang dari luar Kabupaten yang berlatar pendidikan rendah sehingga lebih memilih untuk mencari pekerjaan.Faktor pendidikan responden akan mempengaruhi minat responden dalam memilih metode kontrasepsi yang akan digunakan seperti teori Bouge dalam Lucas (1990) yang menyatakan bahwa pendidikan mempunyai pengaruh yang lebih kuat terhadap fertilitas daripada variabel lain dan menurut Kusumaningrum R. (2011) ${ }^{7}$, pendidikan merupakan salah satu faktor penentu terhadap pengetahuan dan pendapat seseorang mengenai suatu hal, termasuk partisipasi dalam ber-KB. Pendidikan memiliki peranan yang sangat penting dalam menentukan kualitas manusia, dengan pendidikan manusia dianggap akan memperoleh pengetahuan. Semakin tinggi pendidikan, diharapkan hidup manusia semakin berkualitas. Namun tidak demikian yang terjadi pada responden dalam penelitian ini bahwa tingkat pendidikan tidak berhubungan dengan minat terhadap penggunaan kontrasepsi, hal ini menarik karena dari 33 responden yang berminat menggunakan kontrasepsi implant justru responden yang memiliki tingkat pendidikan Sekolah dasar sebanyak 2 orang dan sebaliknya semua responden yang tidak berminat terhadap penggunaan kontrasepsi implant mempunyai latar belakang pendidikan yang lebih tinggi. Hal ini menunjukkan memilih dan menggunakan alat kontrasepsi implant bukan dikarenakan faktor pendidikan, akan tetapi disebabkan oleh faktor lain seperti merasa cemas dan takut terhadap proses pemasangan dan efek samping dari kontrasepsi implant tersebut. Seperti diketahui kontrasepsi implant merupakan kontrasepsi yang memerlukan tindak pembedahan minor untuk memasang/insersi dan pencabutannya, sehingga klien tidak dapat menghentikan sendiri pemakaiannya sesuai dengan 
keinginan tetapi harus pergi ke klinik untuk pencabutan ${ }^{8}$.

Demikian pula dengan pengetahuan, dengan tiga kategori baik, cukup dan kurang menunjukkan 33 responden yang digunakan dalam penelitian ini mempunyai pengetahuan yang sama terhadap metode kontrasepsi implant (tabel 7). Hal ini menunjukkan bahwa pengetahuan terhadap kelebihan dan kekurangan kontrasepsi implant sudah umum diketahui oleh masyarakat luas khususnya di Kec. Gantarang Kab. Bulukumba.Mungkin pengetahuan tentang kontrasepsi implant ini diperoleh dari ibu-ibu yang sudah berpengalaman dalam metode kontrasepsi sehigga dapat dan mudah menyarankan metode kontrasepsi yang mana lebih nyaman digunakan sesuai dengan pengalaman mereka sebelumnya. Hal ini sejalan dengan faktor sumber informasi (tabel 8 dan 12) dimana sumber informasi yang terbanyak diperoleh dari bukan tenaga kesehatan mempengaruhi peminatan responden terhadap metode kontrasepsi non implant lebih banyak dibanding kontrasepsi implant. Diketahui pengetahuan mudah diperoleh dengan cara melihat, mendengar, mencium, rasa dan raba dengan kata lain tingkat pengetahuan yang merupakan domain kognitif mempunyai 6 tingkat yaitu tahu (know), memahami (comprehension), aplikasi (application), analisis (analysis), sintesis (synthesis), dan evaluasi (evaluation) (Notoadmodjo, 2011:12). Walaupun hubungan pengetahuan ibu sebagai responden dengan minat terhadap penggunaan kontrasepsi tidak signifikan dalam penelitian ini, akan tetapi $6,1 \%$ dari ibu dengan pengetahuan yang baik memilih untuk menggunakan kontrasepsi implant dibanding dengan kategori yang lain (Tabel 11). Ini pula yang menurut asumsi peneliti,meskipun mereka hanya sekedar tahu atau pernah mendengar tentang kontrasepsi implant jika tidak dipahami dan diaplikasikan maka tidak akanmembawa perubahan perilaku kearah yang lebih baik untuk menunjang kesehatan termasuk dalam hal berKB.

Sumber informasi memegang peranan penting dalam hal minat seorang ibu dalam memilih dan percaya diri dalam menggunakan kontrasepsi.Menurut teori Pinem, S (2011) yang menyatakan bahwa sumber informasi adalah data yang merupakan kenyataan yang menggambarkan suatu kejadian-kejadian dan kesatuan nyata sehingga pemberian informasi dan penjelasan yang diberikan oleh tenaga maupun yang bukan tenaga kesehatan tentang alat kontrasepsi merupakan bentuk dukungan dan dorongan untuk penggunaan alat kontrasepsi termasuk implant. Pemberian informasi tidak hanya dihitung dari berapa kali mendapatkan informasi, melainkan kejelasan dari informasi yang akan memberikan pengaruh baik terhadap pemahaman sipenerima informasi serta meningkatkan keberhasilan penggunanan metode kontrasepsi.

Dalam penelitian ini, sumber informasi mempunyai hubungan yang erat dengan minat ibu terhadap metode kontrasepsi. Mayoritas ibu yang memilih menggunakan metode kontrasepsi non implant dengan informan dari bukan tenaga kesehatan $(63,6 \%)$ dibanding dengan informan dari tenaga kesehatan $(27,3 \%)$ menunjukkan bahwa keputusan dalam memilih atau penggunaan metode kontrasepsi dipengaruhi pada pengalaman orang-orang disekitaran, mungkin saja berasal dari ibu-ibu yang sudah berpengalaman dalam penggunaan metode kontrasepsi yang mana lebih nyaman digunakan sesuai dengan pengalaman mereka sebelumnya. Tidak menutup kemungkinan informan berupa Bapak-bapak yang mempunyai istri berpengalaman dalam penggunaan metode kontrasepsi implant (Tabel 12). Pada tabel 12 itu juga dengan 9,1\% pengguna kontrasepsi implant menunjukkan adanya peranan yang signifikan dari petugas kesehatan dalam mempromosikan metode kontrasepsi implant pada masyarakat di Kec. Gantarang.Hal 
tersebut sejalan dengan penelitian yang dilakukan oleh Firdawsyi Nuzula (2015) dengan judul faktor-faktor yang berhubungan dengan pemakaian implant pada wanita pasangan usia subur di Tegalsari Kabupaten Banyuwangi dengan hasil analisa data menggunakan uji Chi-Square menunjukkan bahwa $p$ value $=0,000$ yang berarti informasi dari tenaga kesehatan mempunyai hubungan yang signifikan terhadap pemakaian kontrasepsi implant.

\section{KESIMPULAN}

Berdasarkan hasil penelitian yang telah dilakukan dengan judul faktor-faktor yang berhubungan dengan kurangnya minat ibu terhadap penggunaan metode kontrasepsi implant di Wilayah Puskesmas Ponre Kecamatan Gantarang Kabupaten Bulukumba tahun 2016, maka dapat disimpulkan bahwa faktor yang sangat signifikan mempengaruhi kurangnya minat ibu terhadap penggunaan metode kontrasepsi implant adalah sumber informasi.Berdasarkan 33 responden yang diteliti, mayoritas mendapatkan informasi dari yang bukan tenaga kesehatansebanyak 21 orang $(63,6 \%)$ untuk peminatan pada metode kontrasepsi nonimplant, dan tidak ada sama sekali $(0.0 \%)$ untuk metode kontrasepsi implant. Sebaliknya sumber informasi dari tenaga kesehatan sejumlah 9 orang atau $27,3 \%$ yang berminat pada metode kontrasepsi nonimplant, dan 3 orang atau $9,1 \%$ pada metode kontrasepsi implant. Walaupun tidak menutup kemungkinan faktor-faktor lain dapat mempengaruhi.

\section{DAFTAR PUSTAKA}

1. Profil Kesehatan Indonesia 2014. 2015. Jakarta: Kementerian Republik Indonesia (diakses pada tanggal 24 Februari 2015).

2. Andayani, D. 2013. Faktor-faktor Yang Berhubungan Dengan Minat Ibu Dalam Menggunakan Alat Kontrasepsi Implant
Di Wilayah Kerja Puskesmas Ingin Jaya Kabupaten Aceh Besar. JurnalKebidanan U'Budiyah(diakses pada tanggal 21 Oktober 2015).

3. Sastroasmoro, S. Ismael, S. 2014. Dasar - Dasar Metodologi Penelitian KlinisEd 5. Jakarta: Sagung Seto.

4. Munawaroh. 2013. Panduan Memahami Metodologi Penelitian. Jombang: Intimedia Anggota IKAPI.

5. Hidayat, A.A. 2014. Metode Penelitian Kebidanan Dan Teknik Analisis Data Ed2. Jakarta: Salemba Medika.

6. Setiawan, A. Saryono. 2011. Metodologi Penelitian Kebidanan DIII, DIV, S1 dan S2. Yogyakarta: Nuha Medika.

7. Kusumaningrum, R. 2011. Faktor faktor yang Mempengaruhi Pemilihan Jenis kontrasepsi yang digunakan pada Pasangan usia Subur. Fakultas Kedokteran Universitas Diponegoro Semarang(diakses pada tanggal 29 Februari 2016).

8. Pinem, S. 2011. Kesehatan Reproduksi \& Kontrasepsi. Jakarta: TIM. 